\title{
The $\alpha_{1}$-adrenergic receptors: diversity of signaling networks and regulation
}

\author{
Susanna Cotecchia \\ Dipartimento di Fisiologia Generale e Ambientale, Università di Bari, Italy, and Département de Pharmacologie et de \\ Toxicologie, Université de Lausanne, Switzerland
}

\begin{abstract}
The $a_{1}$-adrenergic receptor (AR) subtypes $\left(a_{1 a^{\prime}} a_{1 b^{\prime}}\right.$ and $\left.a_{1 d}\right)$ mediate several physiological effects of epinephrine and norepinephrine. Despite several studies in recombinant systems and insight from genetically modified mice, our understanding of the physiological relevance and specificity of the $a_{1}$-AR subtypes is still limited. Constitutive activity and receptor oligomerization have emerged as potential features regulating receptor function. Another recent paradigm is that $\beta$ arrestins and $G$ protein-coupled receptors themselves can act as scaffolds binding a variety of proteins and this can result in growing complexity of the receptormediated cellular effects. The aim of this review is to summarize our current knowledge on some recently identified functional paradigms and signaling networks that might help to elucidate the functional diversity of the $a_{1}$-AR subtypes in various organs.
\end{abstract}

Keywords: Constitutive activity; oligomerization; $\beta$-arrestin; protein interactions; knock out mice; transgenic mice

\section{Introduction}

Within the large family of $G$ protein-coupled receptors (GPCR), the adrenergic receptors (ARs) mediate the functional effects of catecholamines, like epinephrine and norepinephrine. The AR family includes nine different gene products, three $\beta\left(\beta_{1}, \beta_{2}, \beta_{3}\right)$, three $\alpha_{1}\left(\alpha_{1 a^{\prime}}, \alpha_{1 b}\right.$, and $\alpha_{1 \mathrm{~d}}$, and three $\alpha_{2}\left(\alpha_{2 \mathrm{~A}}, \alpha_{2 \mathrm{~B}}\right.$, and $\left.\alpha_{2 \mathrm{C}}\right)$ receptor subtypes.

The $\alpha_{1}$-AR subtypes are expressed in various organs, including brain, heart, blood vessels, liver, kidney, prostate, and spleen, in which they mediate a variety of functional effects such as modulation of neurotransmission, vasoconstriction, cardiac inotropy, and chronotropy, regulation of metabolism (reviewed in ref. 1). Activation of the three $\alpha_{1}$-AR subtypes causes polyphosphoinositide hydrolysis catalyzed by phospholipase C (PLC) via pertussis toxin-insensitive $\mathrm{G}$ proteins in most tissues where this effect has been examined (1).

Radioligand binding studies in rat tissues initially demonstrated two classes of $\alpha_{1}$-AR binding sites, "A" and "B" with high and low affinity for the $\alpha_{1}$-AR antagonists
WB4101 and phentolamine, respectively. The first $\alpha_{1}$-AR cloned, was unequivocally assigned to the pharmacological $\alpha_{1 \mathrm{~B}}$ subtype and hence named $\alpha_{1 \mathrm{~b}}$-AR. The pharmacological $\alpha_{1 \mathrm{~A}}$ subtype, today identified as $\alpha_{1 \mathrm{a}}-\mathrm{AR}$, was initially cloned from a bovine brain library and inappropriately named $\alpha_{1 \mathrm{C}}-\mathrm{AR}$ or $\alpha_{1 \mathrm{~A} / \mathrm{C}}-\mathrm{AR}$. Finally, the cloned $\alpha_{1 d}$-AR (initially named $\alpha_{1 \mathrm{~A}}-\mathrm{AR}$ or $\alpha_{1 \mathrm{~A} / \mathrm{D}}-\mathrm{AR}$ ) was a novel receptor subtype not clearly identified by previous pharmacological studies (reviewed in ref. 2,3).

Studies aiming to assess the specific functional responses mediated by distinct $\alpha_{1}$-AR subtypes have been hampered by the fact that the subtype-selective drugs are only moderately selective. Recently, studies on genetically modified mice lacking or overexpressing one or more $\alpha_{1}$-AR subtypes have provided some important insight into the functional roles played by distinct receptors. However, our understanding on the functional implications of $\alpha_{1}$-AR heterogeneity in physiological systems is still quite limited.

Extensive mutational analysis performed by our group and other investigators helped to identify the structural

Address for Correspondence: Susanna Cotecchia, Dipartimento di Fisiologia generale e Ambientale, Via Amendola 165/A, 70126 Bari, Italy. E-mail: susanna. cotecchia@unil.ch

(Received 01 August 2010; revised 20 August 2010; accepted 20 August 2010) 
determinants of the $\alpha_{1}$-AR subtypes involved in each of the three main "classical" functional properties of GPCRs: (i) ligand-binding; (ii) receptor activation and coupling to $\mathrm{G}$ protein; and (iii) desensitization. These findings have been reviewed elsewhere $(4,5)$. Beyond these "classical" features, a number of novel functional paradigms have been recently described for GPCRs including receptor constitutive activity (6), oligomerization (7) and interaction with a variety of signaling proteins (8). These functional features imply a growing complexity of signaling and regulation of the $\alpha_{1}$-AR subtypes which might represent the mechanistic basis of their functional specificity in various tissues.

The aim of this review is to summarize our current knowledge on some recently identified functional paradigms and signaling networks that might help to elucidate the functional diversity of the $\alpha_{1}$-AR subtypes in various organs.

\section{Constitutive activity of the $\alpha_{1}$-AR subtypes}

For both the $\alpha_{1 \mathrm{a}}$ and $\alpha_{1 \mathrm{~b}}$-AR mutation-induced and spontaneous constitutive activity have been reported $(9,10)$. Interestingly, most of the known $\alpha$-blockers behave as inverse agonists both at the wild type and constitutively actve mutants of the two receptors (10). Studies on constitutively activating mutations of the $\alpha_{1 b}$-AR provided important insight into the potential molecular mechanisms of GPCR activation (11). In particular, they highlighted the highly conserved E/DRY sequence at the cytoslic end of helix 3 as an important switch of receptor activation.

Interestingly, activating mutations which perturb the helix 3/helix 6 packing of the receptor have been found in both the $\alpha_{1 \mathrm{a}}$ and $\alpha_{1 \mathrm{~b}}$-AR subtypes suggesting common mechanisms of receptor activation (12). These include: (i) mutations of $\mathrm{A} 293^{(6.34)}$ and of A271 $1^{(6.34)}$ in the cytosolic extension of helix 6 in the $\alpha_{1 \mathrm{~b}}$-AR and $\alpha_{1 \mathrm{a}}$-AR, respectively $(9,10)$; (ii) mutations of D142 $2^{(3.49)}$ and $\mathrm{D} 123^{(3.49)}$ of the E/DRY motif in the $\alpha_{1 b}$-AR and $\alpha_{1 a}$-AR, respectively $(10,11)$.

However, some differences in the activation properties can be observed between the $\alpha_{1 \mathrm{a}}$ and $\alpha_{1 \mathrm{~b}}$-AR in recombinant systems measuring the inositol phosphate response. The agonist-independent activity of both the wild type $\alpha_{1 b}$-AR and its constitutively active mutants was significantly higher than that of the wild type $\alpha_{1 \mathrm{a}}$-AR or its mutant. In contrast, the epinephrine-induced inositol phosphate accumulation above basal at the $\alpha_{1 a}$-AR was significantly higher than that at the $\alpha_{1 \mathrm{~b}}$-AR or its constitutively active mutants expressed at comparable levels $(10,13)$. This suggests that in recombinant systems the agonist-occupied $\alpha_{1 a}$-AR has greater efficacy in activating PLC than the $\alpha_{1 b}$-AR whereas its spontaneous or mutation-induced isomerization toward the active states is lower. Only one study reported the opposite showing that in rat neonatal cardiomyocytes a different constitutively active mutant of the $\alpha_{1 \mathrm{a}}$-AR displayed higher basal activity than the analogous mutant of the $\alpha_{1 b}-\operatorname{AR}(14)$. This finding is intriguing and should be further explored.

The properties of the $\alpha_{1 d}$-AR subtype have been investigated very little because its expression as well as the agonist-induced inositol phosphate response mediated by this receptor were often found to be much smaller than those of the other two subtypes $(15,16)$. Constitutively activating mutations of the $\alpha_{1 d}$-AR have not been reported so far. However, an interesting study reported that the $\alpha_{1 \mathrm{~d}}$-AR expressed in rat fibroblasts is constitutively active and internalized (17). In fact, the basal activity of the $\alpha_{1 d}$-AR was 2-fold greater than that of the $\alpha_{1 b}$-AR and was increased following the treatment with the inverse agonist prazosin which caused its redistribution from the intracellular compartments to the plasma membrane. The constitutive activity of the $\alpha_{1 \mathrm{~d}}$-AR was also observed in physiological systems like in aorta and mesenteric arteries where it could inhibited by inverse agonists (18). For the $\alpha_{1 \mathrm{a}}$ or $\alpha_{1 \mathrm{~b}}$-AR constitutive activity in physiological systems has not been investigated.

Altogether, these findings indicate that there might be important differences in the constitutive activity of the $\alpha_{1}$-AR subtypes which could have consequences in their signaling and regulatory properties in vivo. Such differences should be further explored and the elucidation of their physiological implications might represent an important area of investigation.

\section{Oligomerization of the $\alpha_{1}$-AR subtypes}

Findings in the last decade challenged the widely held view of GPCRs functioning as monomeric units. Co-immunoprecipitation of differentially tagged GPCRs or functional complementation of pairs of co-expressed inactive receptor mutants provided strong evidence that GPCR oligomers do exist. The widespread use of biophysical techniques such as fluorescence resonance energy transfer (FRET) or bioluminescence resonance energy transfer (BRET) between GPCRs carrying the appropriate pair of fluorescent/bioluminescent labels suggested oligomerization of a variety of GPCRs. Each technique employed has its own shortcomings: whereas co-immunoprecipitation cannot rule out indirect interaction, energy transfer techniques can only certify that the two partners are in close proximity, not necessarily in immediate contact. However, convergent results obtained through independent methods eventually led to the widespread acknowledgment of the existence of GPCR oligomers (7). 
Both homo- and hetero-oligomerization have been demonstrated for the three $\alpha_{1}$-AR subtypes in recombinant systems (Table 1) $(15,16,19)$. FRET measurements as well as co-immunoprecipitation experiments provided evidence that both the $\alpha$ la and $\alpha$ lb-AR can form homooligomers (19). Oligomerization of the $\alpha_{1 \mathrm{~b}}$-AR did not require the integrity of its $\mathrm{C}$-tail, of two glycophorin motifs or of the N-linked glycosylation sites at its N-terminus. Constitutively active or non-functional $\alpha_{1 b}$-AR mutants displayed the same propensity to oligomerize as the wildtype receptor, indicating that the activation state of the receptor is irrelevant for this process. Receptor oligomerization was not influenced by the agonist epinephrine or by the inverse agonist prazosin. Thus, whether homooligomerization of the $\alpha_{1 \mathrm{a}}$ or $\alpha_{\mathrm{lb}}$-AR has any functional relevance is unknown.

Hetero-oligomers were observed between the $\alpha_{1 \mathrm{a}}$ and the $\alpha_{1 \mathrm{~b}}$-AR subtypes, but not between the $\alpha_{1 b}$-AR and other GPCRs. Interestingly, hetero-oligomerization was found to have an impact on receptor endocytosis (19). Whereas the $\alpha_{1 b}$-AR undergoes agonist-induced internalization, the $\alpha_{1 \mathrm{a}}$-AR does not. However, when the two AR subtypes were co-expressed forming heterodimers, the endocytosis of each monomer could be triggered by stimulation of the other. Colocalization of the two monomers could be seen in endocytic vesicles suggesting that the $\alpha_{1 \mathrm{a}} / \alpha_{1 \mathrm{~b}}$ dimers remained stable throughout the endocytosis process.

An important effect of hetero-oligomerization has been reported for the $\alpha_{1 \mathrm{~d}}$-AR subytpe. In fact, co-expression of the $\alpha_{1 d} \mathrm{AR}$ with the $\alpha_{1 \mathrm{~b}} \mathrm{AR}(15)$ or the $\beta_{2} \mathrm{AR}$ (19) was able to rescue surface expression of the $\alpha_{1 d}-A R$, the majority of which is intracellular when expressed alone in various cell lines. Interestingly, the interaction with the $\alpha_{1 b}$-AR modified the pharmacological profile of the $\alpha_{1 d}$-AR which looses its affinity for its selective ligand BMY7378 when it is co-expressed with the $\alpha_{1 b}$-AR. The $\alpha_{1 b} / \alpha_{1 d}$ dimer behaves as a single functional entity with increased response to norepinephrine relative to either monomer alone. The $\alpha_{1 d}$-AR receptor was long supposed to be little expressed in the heart, as its selective ligand BMY7378 could detect only minimal levels of the receptor. However, these findings should be considered in a new light, given that the $\alpha_{1 b}$ and $\alpha_{1 \mathrm{~d}}$-AR subtypes co-exist in various tissues and the pharmacological profile of the $\alpha_{1 d}$-AR might be different than expected because of oligomerization.

Oligomerization of $\alpha_{1}$-AR subytpes in physiological systems has not been explored so far for lack of appropriate experimental tools. Therefore, the functional relevance of $\alpha_{1}$-AR oligomerization in vivo remains elusive. However, oligomerization might represent an additional mechanism regulating the physiological responses mediated by the $\alpha_{1}$-AR subytpes which are often co-expressed in the same cells. Further exploring the functional correlates of receptor oligomerization and assessing if it occurs in physiological systems might provide interesting information about cross-talk effects at the level of $\alpha_{1}$-AR signaling or regulation.

\section{Signaling pathways of the $\alpha_{1}$-AR subytpes}

It has become increasingly evident that the variety of functional effects mediated by the $\alpha_{1}$-ARs in different organs must imply the activation of multiple signaling pathways beyond activation of PLC via Gq/11. Therefore, several studies have attempted to investigate whether each $\alpha_{1}$-AR subtype may activate distinct signaling pathways, but our knowledge on this issue is still limited.

It has been reported that stimulation of the $\alpha_{1 b}$ and $\alpha_{1 \mathrm{~d}}$-AR can result in the activation of phospholipase A2 in COS- 1 cells (20); the $\alpha_{1 \mathrm{a}}$-AR was not explored. In NIH3T3 cells, the activation of the $\alpha_{1 \mathrm{a}}$ and $\alpha_{1 \mathrm{~b}}$-AR, but not that of the $\alpha_{1 d}$, resulted in the stimulation of p21-ras, PI3-kinase and mitogen-activated protein kinase (MAPK) (21). However, the steps leading to the activation of these pathways seem to differ between the two receptor subtypes.

In hepatocyte derived cells, stimulation of the $\alpha_{1 b}$-AR subtype inhibits interleukin 6 signaling by a MAPK mechanism (22). An interesting microarray study indicated that the $\alpha_{1}$-AR subtypes expressed in Rat fibroblasts have a differential effect on cell cycle genes with the $\alpha_{1 b}$ mediating cell-cycle progression, and the $\alpha_{1 \mathrm{a}}$ and $\alpha_{1 \mathrm{~d}}-\mathrm{AR}$ mediating G1-S cell cycle arrest (23).

Most of the work investigating $\alpha_{1}$-AR signaling has been performed in cardiomyocytes. In fact, hearts of most species express both $\alpha_{1 \mathrm{a}}$ and $\alpha_{1 \mathrm{~b}}$-AR at protein level whereas the expression of $\alpha_{1 d}-A R$ is very low. The $\alpha_{1 a}$-AR predominates in humans, whereas the $\alpha_{1 b}$-AR in rodents. Some seminal studies $(24,25)$ demonstrated that stimulation of the $\alpha_{1}$-ARs in cardiomyocytes induces a hypertrophic response accompanied by the activation of early genes (c-fos, c-jun, egr-1) upreagulation of contractile proteins (myosin light chain-2) and reactivation of embryonic genes (atrial natriuretic factor (ANF), $\beta$-myosin heavy chain, skeletal $\alpha$-actin).

Various studies provided clear evidence for the involvement of both the PLC-MAPK pathway (26) and

Table 1. Oligomerization of the $\alpha_{1}$-adrenergic receptor subtypes.

\begin{tabular}{lllll}
\hline Receptors & Trafficking & Pharmacology & Signaling & Ref. \\
\hline$\alpha_{1 \mathrm{a}} / \alpha_{1 \mathrm{~b}}$ & Co-endocytosis & No change & - & 19 \\
$\alpha_{1 \mathrm{~b}} / \alpha_{1 \mathrm{~d}}$ & $\begin{array}{l}\uparrow \alpha_{1 \mathrm{~d}} \text { Surface } \\
\text { expression }\end{array}$ & $\begin{array}{l}\downarrow \alpha_{1 \mathrm{~d}} \text { Affinity for } \\
\text { selective ligands }\end{array}$ & $\uparrow$ Signaling & 15 \\
$\alpha_{1 \mathrm{~d}} / \beta_{2}$ & $\begin{array}{l}\uparrow \alpha_{1 \mathrm{~d}} \text { Surface } \\
\text { expression }\end{array}$ & - & - & 16 \\
& co-endocytosis & & - & \\
Homo- & - & - & 15,19 \\
oligomers & & & \\
$\alpha_{1 \mathrm{a}}, \alpha_{1 \mathrm{~b}}, \alpha_{1 \mathrm{~d}}$ & & & \\
\hline
\end{tabular}


Rho-signaling (27) in the $\alpha_{1}$-AR-induced hypertrophic response in cardiomyocytes. A recent study supports these earlier findings suggesting that $\alpha_{1}$-AR-induced cardiac hypertrophy is mediated by three parallel pathways: G12/13-Rho-JNK, Gq-JNK (Rho-independent) and G $\beta \gamma$ (JNK independent) (28). Recent findings have demonstrated that the $\alpha_{1}$-ARs endogenously expressed in rat neonatal cardiomocytes promote RhoA-activation via a mechanism that requires G12 and the Rho-guanine nucleotide exchange factor AKAP-Lbc and this pathway mediates hypertrophy (29).

The respective role in stimulating cardiac hypertrophy of the two $\alpha_{1}$-AR subtypes expressed in heart, the $\alpha_{1 \mathrm{a}}$ and $\alpha_{1 \mathrm{~b}}-\mathrm{AR}$, does not emerge clearly from the in vitro studies published so far probably because of the limited selectivity of the pharmacological tools available. In one study on rat neonatal cardiomyocytes, a constitutively active form of the $\alpha_{1 \mathrm{a}}$-AR activated gene expression of the ANF, whereas the analogous constitutively active mutant of the $\alpha_{1 b}$-AR stimulated gene expression of c-fos, but not of ANF (14). However, these findings are intriguing considering that other studies reported the opposite and that overexpression of the $\alpha_{1 b}$-AR in transgenic mice resulted in a marked increase in ANF (see below). In the future, it would be interesting to carry on a systematic investigation of different signaling pathways comparing the $\alpha_{1}$-AR subtypes expressed in the same cellular systems and to correlate these findings with the growing information provided by in vivo studies on genetically modified mice (see below).

\section{Regulatory mechanisms and $\beta$ arrestin interaction at the $\alpha_{1}$-AR subytpes}

The $\alpha_{1}$-AR subtypes display quite divergent regulatory properties. In fact, the $\alpha_{1 b}$-AR in recombinant systems undergoes rapid phospohorylation, desensitization and endocytosis upon exposure to the agonist (30-32). Desensitization involves phosphorylation of residues in the $\mathrm{C}$-tail of the receptor mediated by $\mathrm{G}$ protein-coupled receptor kinases (GRKs) (31). The endocytosis of the $\alpha_{1 b}$-AR occurs via clathrin-coated vesicles and seems to involve $\beta$ arrestins (32).

In contrast, the $\alpha_{1 a}$-AR expressed in rat-1 fibroblasts is poorly phosphorylated and desensitized compared to the $\alpha_{1 b}$-AR (33). In addition, it undergoes very modest agonist-induced endocytosis (32).

Fewer studies have investigated the desensitization of the $\alpha_{1 \mathrm{~d}}$-AR probably because of its poor expression in recombinant systems. It has been reported that noradrenaline and direct activation of protein kinase $\mathrm{C}$ induce phosphorylation of the $\alpha_{1 \mathrm{~d}}$-AR and this correlates with desensitization of the receptor (34). However, desensitization of the $\alpha_{1 d}$-AR was not compared with that of the other two subtypes in this study.

Overall, the impact of $\alpha_{1}$-AR desensitization in physiological systems where the receptors are endogenously expressed has been poorly investigated, as it is the case for most GPCRs. Therefore, what is the impact of different regulatory properties of the $\alpha_{1}$-AR subtypes on complex functions like vasoconstriction, metabolic response, and others, is unknown.

Interestingly, the different regulatory features of the $\alpha_{1 \mathrm{a}}$ and $\alpha_{1 \mathrm{~b}}$-AR seem to correlate with their pattern of interaction with $\beta$ arrestins. In fact, the results from both co-immunoprecipitation experiments and ßarrestin translocation assays indicated that the agonist-induced interaction of the $\alpha_{1 \mathrm{a}}$-AR with $\beta$ arrestin was much weaker than that of the $\alpha_{1 b}$-AR (32). The interaction of $\beta$ arrestin with the $\alpha_{1 \mathrm{~d}}$-AR has not been directly explored so far.

These differences in receptor/ $\beta$ arrestin interaction might have broader implications in $\alpha_{1}$-AR mediated signaling because of the well established role played by ßarrestins in coordinating a variety of signaling networks (35). In particular, it is well established that $\beta$ arrestins are scaffolds for components of the MAPK cascade thus mediating MAPK activation induced by various GPCRs. Investigation of $\beta$ arrestin-mediated signaling at the $\alpha_{1}$-AR subtypes is an interesting area of investigation which has been poorly explored so far and might represent one of the mechanisms contributing to the variety of the receptor-mediated-responses.

\section{Proteins interacting with different $\alpha_{1}$-AR subtypes}

One of the most recent paradigms is that GPCRs can bind a variety of proteins and this can promote multiple signaling events which results in growing complexity of the receptor-mediated cellular effects (8)

A number of approaches have been followed to identify novel proteins interacting with the $\alpha_{1}$-ARs, including yeast two-hybrid screen using cytosolic portions of the receptors as bait, pull-down or in vitro overlay assays using purified proteins, co-immunoprecipitation of receptor-protein complexes from recombinant or native cells, FRET or BRET technology in cells. These studies resulted in the identification of a variety of proteins interacting with the $\alpha_{1}$-AR subtypes, several of them in a receptor subtype selective pattern (Table 2).

The $\alpha_{1 a}$-AR subtype contains a PDZ binding sequence G-E-E-V at its C-terminus that can be expected to give rise to PDZ-domain mediated interactions. An early report, at the issue of a yeast two-hybrid screen, identified the type III PDZ domain of nNOS (neuronal nitric oxide synthase) as a potential $\alpha_{1 a}-A R$ interacting protein (36) However, 
Table 2. Proteins interacting with the $\alpha_{1}$-adrenergic receptor subtypes.

\begin{tabular}{llllc}
\hline Receptor & Partner & Binding site & Functional role & Ref. \\
\hline$\alpha_{1 \mathrm{a}} \alpha_{1 \mathrm{~b}} \alpha_{1 \mathrm{~d}}$ & nNOS & Unknown & Unknown & 36 \\
$\alpha_{1 \mathrm{a}}$ & Tolloid & C-tail & $\downarrow$ Surface expression & 37 \\
$\alpha_{1 \mathrm{a}}$ & RGS2 & i3 loop(K219- & $\downarrow$ Gq signaling & 38 \\
& & S220-R238) & & \\
$\alpha_{1 \mathrm{~b}}$ & AP50 & C-tail (8 Arg) & $\uparrow$ Endocytosis & 40 \\
$\alpha_{1 \mathrm{~b}}$ & Ezrin & C-tail (8 Arg) & $\uparrow$ Recycling & 41 \\
$\alpha_{1 \mathrm{~b}}$ & Spinophilin & i3 loop & $\downarrow \mathrm{Ca}^{2+}$ signaling & 43 \\
& & & induced by RG2 & \\
$\alpha_{1 \mathrm{~d}}$ & Syntrophins & C-term (ETDI) & Stabilization of & 44 \\
& & & receptor at cell surface & \\
$\alpha_{1 \mathrm{~b}} \alpha_{1 \mathrm{~d}}$ & gC1qR & C-tail (Arg) & Unknown & 42 \\
\hline
\end{tabular}

co-immunoprecipitation studies, while confirming this interaction, failed to highlight selectivity for the $\alpha_{1 \mathrm{a}}$-AR subtype since all three $\alpha_{1}$-AR subtypes could be co-immunoprecipitated with nNOS and this even when they were lacking their C-terminus. This interaction appeared to be without apparent physiological implications in spite of the known role of NO in the regulation of blood pressure and of nNOS as local metabolic inhibitor of $\alpha_{1}$-AR -mediated vasoconstriction.

Another study reported that the CUB5 domain of mammalian tolloid (mTLD), a zinc-finger matrix metalloprotease of the astacin family, interacted with $\alpha_{1 a}$-AR C-tail in a yeast two hybrid screen (37). Overexpression of mTLD reduced the number of cell surface receptors without affecting total receptor level or affinity when transiently expressed in HEK293 cells. No mechanism was proposed to account for the observed phenomena.

Interesting prospects were opened by the report of the direct interaction between RGS2 (regulator of G protein signaling 2) and the third intracellular loop of the $\alpha_{1 a}-A R$ (38). RGS proteins are well characterized inhibitors of heterotrimeric $\mathrm{G}$ protein function, acting as GAPs (GTPase activating proteins) to increase the rate of GTP hydrolysis at $\mathrm{G} \alpha$ subunits and thus terminate signaling. More than 30 RGS proteins have been identified so far, but many RGS proteins can non-selectively bind to and inhibit Gai/o and Gaq11 in reconstituted systems, suggesting that other factors may regulate their specificity for a particular signaling pathway. RGS2 was found to interact with the $\alpha_{1 a}$-AR third intracellular loop confirming what previously shown for other Gq-coupled receptors, namely the cholinergic muscarinic M1, M3, and M5 receptors (39) and it inhibited agonist-induced inositol phosphate responses without affecting ligand binding.

Two main interacting partners were pulled out of a yeast two-hybrid screen for the $\alpha_{1 b}$-AR: the $\mu 2$ (or AP50) subunit of the clathrin adaptor complex AP2 (40) and ezrin, a member of the ezrin-radixin-moesin (ERM) protein family (41). The AP2 complex is part of the endocytic machinery mediating clathrin-dependent endocytosis of membrane proteins and it is recruited to agonist-activated GPCRs through the intermission of ßarrestins. Binding of AP50 relied on a basic stretch of eight arginines in the proximal C-tail of the receptor. Direct association of the $\alpha_{1 b}$-AR to AP50 contributed to the agonist-induced internalization of the receptor as demonstrated by the fact that a receptor mutant lacking the AP50 binding motif was delayed in internalization. The presence of the eight arginine motif in the C-tail of a GPCR is not common, which rules out the hypothesis that direct AP50 interaction is a common mechanism for clathrin-mediated endocytosis. Interestingly, this feature is shared by the $\alpha_{1 d}$-AR, which contains a stretch of seven positive charges in its $\mathrm{C}$-tail, but no studies were undertaken using this receptor subytpe.

In addition to AP50, the same yeast two-hybrid screen identified ezrin as a potentially direct binding partner of the $\alpha_{1 b}$-AR (41). Ezrin belongs to the ERM family of proteins, primarily described as linkers between membrane proteins and cortical actin. Ezrin interactions with polytopic membrane proteins generally occur through the adaptor proteins EBP50 (NHERF1) and E3KARP (NHERF2). So far, a role for the ERM proteins in GPCR trafficking was inferred from the finding that NHERF1 binding to some GPCRs promoted their recycling, depending on its binding to ERM proteins. The $\alpha_{1 b}$-AR is the first GPCR for which a direct interaction with ezrin has been found. Disruption of this interaction by overexpression of a dominant negative mutant of ezrin inhibited receptor reycling after internalization, as did actin depolymerization. However, ezrin was also shown to be involved in the remodelling of the actin cytoskeleton, in the modulation of Rho-signaling (by binding to Rho-GTP dissociation inhibitor and thourgh direct association to several Rho-GTP/GDP exchange factors) as well as in anchoring of protein kinase A. Therefore, it would be interesting to test whether ezrin is also involved in $\rho$-signaling mediated by the $\alpha_{1 b}$-AR.

Another protein, the receptor for globular "Heads" of clq (gClqR), was reported to interact with the same arginine-rich sequence in the $\alpha_{1 b}$ and the $\alpha_{1 d}$-AR (42). $\mathrm{gClqR}$ is a glycoprotein mainly displaying intracellular localization, but also present on the surface of macrophages and $\mathrm{T}$ cells through anchoring to $\beta$-integrin, where it is part of a complement receptor. No functional relevance was demonstrated for its interaction with the $\alpha_{1}$-ARs.

An interesting protein found to interact with the $\alpha_{1 b}$-AR is spinophilin which interacts with other GPCRs, including the $\alpha_{2}$-AR, as well as with the $\mathrm{N}$-terminal domain of RGS proteins (RGS1, 2, 4, and 16) which participates in GPCR recognition (43). Thus spinophilin might represent an interesting functional bridge between RGS and $\alpha_{1} \mathrm{AR}$ subtypes that don't bind RGS, like the $\alpha_{1 b}$ AR. In fact, it has been found that spinophilin increases the RGS2-induced 
inhibition of the $\alpha_{1 b}$-AR calcium response. These data offer a glimpse into a potentially more general regulatory mechanisms of GPCR function by spinophilin.

The $\alpha_{1 d}-A R$ was for a long time a "poor relative" to the other $\alpha_{1}$ AR subtypes, the $\alpha_{1 \mathrm{~A}}$ and $\alpha_{1 \mathrm{~B}}$ because poorly expressed at the cell surface in heterologous systems, probably because of its long N-terminus. This peculiarity hampered the investigation of its potential interactions with other proteins. Apart from the above mentioned interaction with gClqR, whose functional implications are unknown (42), another interacting partner of the $\alpha_{1 d}$-AR was $\alpha$-syntrophin (44). $\alpha$-syntrophin, a protein containing one PDZ domain and two $\mathrm{PH}$ (pleckstrin homology) domains, specifically recognized the C-tail of the $\alpha_{1 d}$-AR, but not that of the $\alpha_{1 a}$ or $\alpha_{1 b}$, in the yeast twohybrid assay. The PDZ domains of syntrophin isoforms $\alpha$, $\beta 1$, and $\beta 2$, but not $\gamma 1$ or $\gamma 2$, could interact with the $\alpha_{1 d} A R$ $\mathrm{C}$-tail. The $\alpha_{1 \mathrm{~d}}$-AR possesses the C-terminal sequence E-T-D-I, whose mutation impaired syntrophin binding to the receptor and markedly decreased norepinephrineinduced inositol phosphate accumulation. This mutation also dramatically decreased receptor expression levels. Taken altogether these results suggested that syntrophins act to maintain the stability of the $\alpha_{1 d}$-AR through a PDZ-mediated interaction.

Altogether these findings indicate a rather complex and heterogeneous pattern of receptor/protein interactions whose physiological implications are far from being fully elucidated. The direct interaction of $\alpha_{1} \mathrm{AR}$ subtypes with selected partners identified in recombinant systems might result in new mechanisms of receptor signaling and regulation. Since these mechanisms might be specific for distinct receptors or cell types, the study of these interactions is an interesting approach to better understand the functional specificity of the receptors. However, this would require a systematic proteomic approach in different tissues expressing the $\alpha_{1} A R$ subtypes as well as good experimental tools to investigate its functional implications.

\section{Insights from genetically modified mice}

Recently, mouse lines carrying genetic modifications of the $\alpha_{1}$-AR subtypes have provided interesting information on the in vivo functions of the receptors giving some insight into the specificity of their role. The $\alpha_{1 b}$-AR knock out (KO) mouse was the first model to be created (45) and it was characterized for a number of functional parameters. The $\alpha_{1 b}$ KO mice displayed: (i) decreased blood pressure response to phenylephrine with normal resting pressure (45); (ii) hyperinsulinemia, insulin resistance and high fat diet-induced obesity (46); and (iii) behavioral changes including blunted locomotor response to drugs of abuse and markedly decreased sensitivity to morphine and cocaine (47). Other mice carrying genetic modifications of the $\alpha_{1}$-AR subtypes have been mainly characterized for their cardiovascular phenotype (Table 3 ) thus allowing to build a more comprehensive picture of the functional role of each receptor in the cardiovascular system.

Both the $\alpha_{1 \mathrm{a}}$ and $\alpha_{1 \mathrm{~d}}$-AR KO mice displayed decreased resting blood pressure as well as phenylephrine stimulated pressure response $(48,49)$. The fact that the acute response to phenylephrine is decreased in all three KO mice indicates that the $\alpha_{1 a^{\prime}} \alpha_{1 b}$ and $\alpha_{1 d}$-AR all contribute to the regulation of the vascular tone. However, the contribution of the $\alpha_{1 \mathrm{a}}$ and $\alpha_{1 \mathrm{~d}}$-AR subtypes is prominent because deletion of either one of the two receptors leads also to decreased resting blood pressure. This can be explained by the fact that the $\alpha_{1 \mathrm{a}}$-AR prevails in distributing arteries (mesenteric, renal) (48) and the $\alpha_{1 d}$-AR in large conducting arteries (aorta and carotid) (49), whereas the expression of the $\alpha_{1 b}$-AR is minor in all arteries.

Studies on genetically modified mice have also provided interesting insight into the role of the $\alpha_{1}$-AR in cardiac function and hypertrophy. As mentioned above, the $\alpha_{1 \mathrm{a}}$ and $\alpha_{1 \mathrm{~b}}$-AR subtypes are both expressed in cardiomyocytes with the $\alpha_{1 \mathrm{a}}$ predominating in humans and the $\alpha_{1 \mathrm{~b}}$ in rodents. Transgenic mice overexpressing a constitutively active $\alpha_{1 b}$-AR mutant specifically in the heart display cardiac hypertrophy without any change in blood pressure (50). This supports previous evidence that stimulation of $\alpha_{1}$-ARs in cardiomyocytes in vitro leads to a hypertrophic response (24). This finding is also consistent with the role played by the Gq/PLC pathway in heart as demonstrated by the fact that transgenic mice overexpressing a constitutively active Gaq develop cardiac hypertrophy (51).

Interestingly, another transgenic mouse overxepressing a different constitutively active $\alpha_{1 b}$-AR mutant, under the control of the receptor own promoter, displayed a more complex phenotype characterized by cardiac hypertrophy as well as autonomic failure (52). This confirms a direct role of the $\alpha_{1 b}$-AR in cardiac hypertrophy, but indicates that broader effects occur when the receptor is generally overexpressed.

Mice overexpressing constitutively active mutant of the $\alpha_{1 \mathrm{a}}$-AR subtype have not been generated. However, the role of the $\alpha_{1 \mathrm{a}}$-AR in heart growth in vivo has been demonstrated by studies on double KO mice carrying deletions of both the $\alpha_{1 \mathrm{a}}$ and $\alpha_{1 \mathrm{~b}}$-AR (53) which displayed several abnormalities including: (i) reduced growth of the heart after birth; (ii) reduced cardiac output; and (iii) increased mortality after pressure overload. These findings demonstrate that both the $\alpha_{1 a}$ and $\alpha_{1 b}$-AR play an important role in heart growth after birth and their integrity is required to maintain correct heart function.

These changes were, however, sex specific since they were observed in males, but not in females. This might be explained by the fact that females have a lower sympathetic tone and the growth of their hearts is less dependent on the $\alpha_{1}$-ARs. 
Cardiac hypertrophy was not observed in transgenic mice with cardiac-specific overexpression of the wild type $\alpha_{1 \mathrm{a}}$ or $\alpha_{1 \mathrm{~b}}$-AR subtype $(54,55)$ despite the fact that they displayed increased expression of ANF. This is unlike the phenotype of mice overexpressing the constitutively active $\alpha_{1 b}$-AR mutant (50). This difference might be due to the fact that the signaling of a constitutively active mutant is somehow different or has greater efficacy than that of the wild-type receptor.

However, transgenic mice overexpressing either the $\alpha_{1 \mathrm{a}}$ or $\alpha_{1 \mathrm{~b}}$-AR subtype in the heart provided a number of novel findings on the functional role of these receptors in heart. In fact, in the heart of the $\alpha_{1 b}$-AR transgenic mice left ventricular contraction in response to $\beta$-agonists was depressed (55). Interestingly, it was found that dampening of $\beta$-AR signaling through adenylate cyclase was due to activation of a pertussis-sensitive inhibitory $\mathrm{G}$ protein. This clearly suggests that when overexpressed $\alpha_{1}$-ARs can couple to inhibitory G proteins.

In conclusion, as summarized in Figure 1, studies on mice carrying genetic modifications of the $\alpha_{1}$-AR genes have provided evidence that: (a) all three $\alpha_{1}$-AR

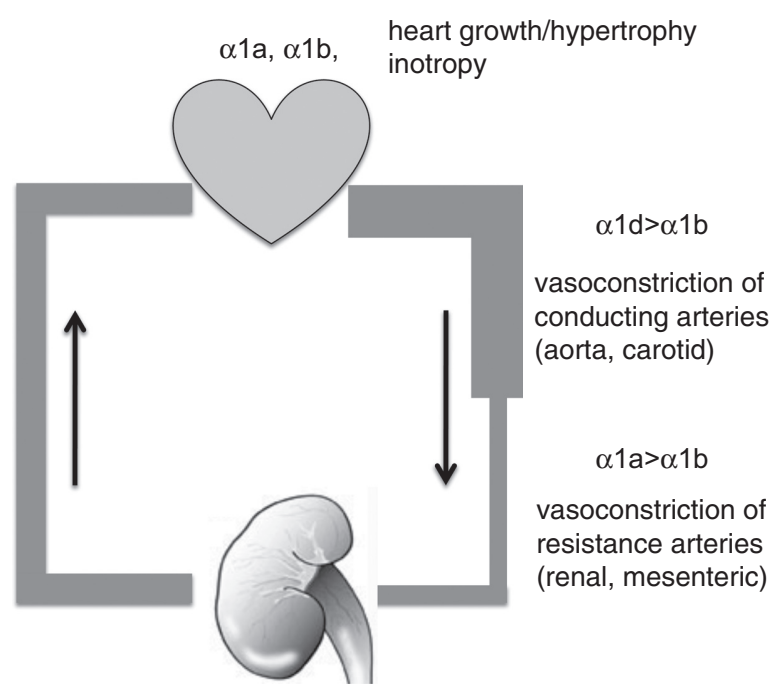

Figure 1. The $\alpha_{1}$-adrenergic receptor subtypes in the cardiovascular system. This figure summarizes the main roles played by distinct $\alpha_{1}$-AR subtypes in the cardiovascular system highlighted by studies on genetically modified mice.

Table 3. Cardiovascular phenotype of mice carrying genetic modifications of different $\alpha_{1}$-adrenergic receptor subtypes.

\begin{tabular}{|c|c|c|c|}
\hline Receptor & Genetic modification & Phenotype & Ref. \\
\hline$\alpha_{1 b}$ & Gene deletion & $\begin{array}{l}\downarrow \text { Resting blood pressure } \\
\downarrow \text { Blood pressure response to phenylephrine }\end{array}$ & 48 \\
\hline$\alpha_{1 a}$ & Overexpression/heart-specific promoter & $\begin{array}{l}\uparrow \text { Contractile response } \\
\uparrow \text { Survival } \\
\uparrow \text { ANF mRNA } \\
\text { No hypertrophy } \\
\uparrow \text { Post-ischemic protection }\end{array}$ & 54 \\
\hline$\alpha_{1 \mathrm{~b}}$ & Gene deletion & $\begin{array}{l}\text { Normal resting blood pressure } \\
\downarrow \text { Blood pressure response to phenylephrine } \\
\downarrow \text { Vasoconstriction }\end{array}$ & 45 \\
\hline$\alpha_{1 b}$ & Overexpression/heart-specific promoter & $\begin{array}{l}\uparrow \text { Phospholipase C activity } \\
\uparrow \text { ANF mRNA } \\
\text { No hypertrophy } \\
\downarrow \text { Contractile and heart rate response to } \beta \text {-AR }\end{array}$ & 55 \\
\hline $\operatorname{CAM} \alpha_{1 \mathrm{~b}}$ & Overexpression/heart-specific promoter & $\begin{array}{l}\uparrow \text { Phospholipase C activity } \\
\uparrow \text { Hypertrophy } \\
\uparrow \text { ANF mRNA } \\
\text { Normal blood pressure }\end{array}$ & 50 \\
\hline $\mathrm{CAM} \alpha_{1 \mathrm{~b}}$ & Overexpression/receptor promoter & $\begin{array}{l}\downarrow \text { Contractile response to } \beta \text {-AR } \\
\text { Autonomic failure } \\
\uparrow \text { Hypertrophy }\end{array}$ & 52 \\
\hline$\alpha_{1 \mathrm{a}} \alpha_{1 \mathrm{~b}}$ & Double gene deletion & $\begin{array}{l}\text { In males Normal resting blood pressure } \\
\downarrow \text { Cardiac growth after birth } \\
\downarrow \text { Heart rate, } \downarrow \text { cardiac output } \\
\downarrow \text { Basal ERK activity } \\
\uparrow \text { Mortality to pressure overload } \\
\text { Contraction abnormalities }\end{array}$ & 53 \\
\hline$\alpha_{1 \mathrm{~d}}$ & Gene deletion & $\begin{array}{l}\downarrow \text { Resting blood pressure } \\
\downarrow \text { Blood pressure response to phenylephrine } \\
\downarrow \text { Vasoconstriction }\end{array}$ & 49 \\
\hline$\alpha_{1 \mathrm{~d}} \alpha_{1 \mathrm{~b}}$ & Double gene deletion & $\begin{array}{l}\downarrow \text { Resting blood pressure } \\
\downarrow \downarrow \text { Blood pressure response to phenylephrine } \\
\downarrow \downarrow \text { Vasoconstriction }\end{array}$ & 57 \\
\hline
\end{tabular}


subtypes contribute to the regulation of blood pressure with a prominent role for the $\alpha_{1 \mathrm{a}}$ and $\alpha_{1 \mathrm{~d}}$; (b) both the $\alpha_{1 \mathrm{a}}$ and $\alpha_{1 \mathrm{~b}}$-AR play a role in cardiac pathological hypertrophy (independent from pressure overload) or physiological hypertrophy associated with postnatal growth; and (c) the $\alpha_{1}$-ARs maintain normal heart function as demonstrated by the fact that the double deletion of the $\alpha_{1 \mathrm{a}}$ and $\alpha_{\mathrm{lb}}$-AR results in some features of failing heart.

Other interesting features of the $\alpha_{1}$-AR subtypes have emerged from studies on the genetically modified mice including their effects on heart contractile function, cardiac rhythm and protection from ischemic injury (56). Additional studies are required to gain a deeper understanding of these complex effects.

\section{Conclusions and perspectives}

In the past years, we have gained significant information of some molecular properties and functional implications of the $\alpha_{1}$-AR subtypes both from in vitro and in vivo studies.

Several studies focused on individual receptor subtypes whereas only few others attempted to compare the behavior of different receptors in similar experimental conditions. This latter approach should be implemented in future studies, both in vitro and in vivo, to better assess differences and similarities among the three $\alpha_{1}-A R$ subtypes.

The elucidation of receptor-mediated signaling events in time and space will depend on a much deeper understanding of the interactions among receptors and signaling molecules which has recently emerged as an important paradigm in the GPCR field. Beyond receptor oligomerization (Table 1), a number of novel proteins have been found to interact with the $\alpha_{1}$-AR subtypes (Table 2), but for most of these interactions the functional implications are elusive. The vast majority of studies on $\alpha_{1}$-AR subtypes have been performed in recombinant systems. A big challenge in the future will be to explore the functional implications of a variety of interactions in different tissues and physiological conditions. The $\alpha_{1}$-AR subtypes are important regulators of several physiological parameters as highlighted by studies in genetically modified mice (Table 3), and further investigation on this receptor system might have new interesting implications in pharmacology and drug development.

\section{Declaration of interest}

This work was supported by the Fonds National Suisse de la Recherche Scientifique (grant n.3100A0-100703).

\section{References}

1. Graham RM, Perez DM, Hwa J, Piascik MT. alpha 1-adrenergic receptor subtypes. Molecular structure, function, and signaling. Circ Res 1996, 78, 737-749.

2. Michel MC, Kenny B, Schwinn DA. Classification of alpha 1-adrenoceptor subtypes. Naunyn Schmiedebergs Arch Pharmacol 1995, 352, 1-10.

3. Schwinn DA, Johnston GI, Page SO, Mosley MJ, Wilson KH, Worman NP, Campbell S, Fidock MD, Furness LM, ParrySmith DJ. Cloning and pharmacological characterization of human alpha-1 adrenergic receptors: sequence corrections and direct comparison with other species homologues. J Pharmacol Exp Ther 1995, 272, 134-142.

4. Cotecchia S, Stanasila L, Diviani D, Björklöf K, Rossier O, Fanelli F. Structural determinants involved in the activation and regulation of $\mathrm{G}$ protein-coupled receptors: lessons from the alpha1adrenegic receptor subtypes. Biol Cell 2004, 96, 327-333.

5. Cotecchia S, Björklöf K, Rossier O, Stanasila L, Greasley P, Fanelli F. The alphalb-adrenergic receptor subtype: molecular properties and physiological implications. J Recept Signal Transduct Res 2002, 22, 1-16.

6. Costa T, Cotecchia S. Historical review: Negative efficacy and the constitutive activity of G-protein-coupled receptors. Trends Pharmacol Sci 2005, 26, 618-624.

7. Angers S, Salahpour A, Bouvier M. Dimerization: an emerging concept for $\mathrm{G}$ protein-coupled receptor ontogeny and function. Annu Rev Pharmacol Toxicol 2002, 42, 409-435.

8. Ritter SL, Hall RA. Fine-tuning of GPCR activity by receptorinteracting proteins. Nat Rev Mol Cell Biol 2009, 10, 819-830.

9. Kjelsberg MA, Cotecchia S, Ostrowski J, Caron MG, Lefkowitz RJ Constitutive activation of the alpha 1B-adrenergic receptor by all amino acid substitutions at a single site. Evidence for a region which constrains receptor activation. J Biol Chem 1992, 267, 1430-1433.

10. Rossier O, Abuin L, Fanelli F, Leonardi A, Cotecchia S. Inverse agonism and neutral antagonism at alpha(1a)- and alpha(1b)adrenergic receptor subtypes. Mol Pharmacol 1999, 56, 858-866.

11. Scheer A, Fanelli F, Costa T, De Benedetti PG, Cotecchia S. The activation process of the alpha1B-adrenergic receptor: potential role of protonation and hydrophobicity of a highly conserved aspartate. Proc Natl Acad Sci USA 1997, 94, 808-813.

12. Greasley PJ, Fanelli F, Rossier O, Abuin L, Cotecchia S. Mutagenesis and modelling of the alpha(1b)-adrenergic receptor highlight the role of the helix $3 /$ helix 6 interface in receptor activation. Mol Pharmacol 2002, 61, 1025-1032.

13. Theroux TL, Esbenshade TA, Peavy RD, Minneman KP. Coupling efficiencies of human alpha 1-adrenergic receptor subtypes: titration of receptor density and responsiveness with inducible and repressible expression vectors. Mol Pharmacol 1996, 50, 1376-1387.

14. McWhinney C, Wenham D, Kanwal S, Kalman V, Hansen C, Robishaw JD. Constitutively active mutants and the alpha(1b)adrenergic receptor subtypes reveal coupling to different signaling pathways and physiological responses in rat cardiac myocytes. J Biol Chem 2000, 275, 2087-2097.

15. Hague C, Uberti MA, Chen Z, Hall RA, Minneman KP. Cell surface expression of alpha1D-adrenergic receptors is controlled by heterodimerization with alpha1B-adrenergic receptors. J Biol Chem 2004, 279, 15541-15549.

16. Uberti MA, Hague C, Oller H, Minneman KP, Hall RA. Heterodimerization with beta2-adrenergic receptors promotes surface expression and functional activity of alpha1D-adrenergic receptors. J Pharmacol Exp Ther 2005, 313, 16-23.

17. García-Sáinz JA, Torres-Padilla ME. Modulation of basal intracellular calcium by inverse agonists and phorbol myristate acetate in rat-1 fibroblasts stably expressing alphald-adrenoceptors. FEBS Lett 1999, 443, 277-281.

18. Gisbert R, Ziani K, Miquel R, Noguera MA, Ivorra MD, Anselmi E, D'Ocon P. Pathological role of a constitutively active population of alpha(1D)-adrenoceptors in arteries of spontaneously hypertensive rats. Br J Pharmacol 2002, 135, 206-216. 
19. Stanasila L, Perez JB, Vogel H, Cotecchia S. Oligomerization of the alpha 1a- and alpha $1 \mathrm{~b}$-adrenergic receptor subtypes. Potential implications in receptor internalization. J Biol Chem 2003, 278, 40239-40251.

20. Perez DM, DeYoung MB, Graham RM. Coupling of expressed alpha 1B- and alpha 1D-adrenergic receptor to multiple signaling pathways is both $\mathrm{G}$ protein and cell type specific. Mol Pharmacol 1993, 44, 784-795.

21. Hu ZW, Shi XY, Lin RZ, Hoffman BB. Contrasting signaling pathways of alpha1A- and alpha1B-adrenergic receptor subtype activation of phosphatidylinositol 3-kinase and Ras in transfected NIH3T3 cells. Mol Endocrinol 1999, 13, 3-14.

22. Nguyen VA, Gao B. Cross-talk between alpha(1B)-adrenergic receptor (alpha(1B)AR) and interleukin-6 (IL-6) signaling pathways. Activation of alpha(1b)AR inhibits il-6-activated STAT3 in hepatic cells by a p42/44 mitogen-activated protein kinase-dependent mechanism. J Biol Chem 1999, 274, 35492-35498.

23. Gonzalez-Cabrera PJ, Shi T, Yun J, McCune DF, Rorabaugh BR, Perez DM. Differential regulation of the cell cycle by alpha1adrenergic receptor subtypes. Endocrinology 2004, 145, 5157-5167.

24. Iwaki K, Sukhatme VP, Shubeita HE, Chien KR. Alpha- and betaadrenergic stimulation induces distinct patterns of immediate early gene expression in neonatal rat myocardial cells. fos/jun expression is associated with sarcomere assembly; Egr-1 induction is primarily an alpha 1-mediated response. J Biol Chem 1990, 265, 13809-13817.

25. Knowlton KU, Michel MC, Itani M, Shubeita HE, Ishihara K, Brown JH, Chien KR. The alpha 1A-adrenergic receptor subtype mediates biochemical, molecular, and morphologic features of cultured myocardial cell hypertrophy. J Biol Chem 1993, 268, 15374-15380.

26. Ramirez MT, Sah VP, Zhao XL, Hunter JJ, Chien KR, Brown $\mathrm{JH}$. The MEKK-JNK pathway is stimulated by alphal-adrenergic receptor and ras activation and is associated with in vitro and in vivo cardiac hypertrophy. J Biol Chem 1997, 272, 14057-14061.

27. Sah VP, Hoshijima M, Chien KR, Brown JH. Rho is required for Galphaq and alphal-adrenergic receptor signaling in cardiomyocytes. Dissociation of Ras and Rho pathways. J Biol Chem 1996, 271, 31185-31190.

28. Maruyama Y, Nishida M, Sugimoto Y, Tanabe S, Turner JH, Kozasa T, Wada T, Nagao T, Kurose H. Galpha(12/13) mediates alpha(1)-adrenergic receptor-induced cardiac hypertrophy. Circ Res 2002, 91, 961-969.

29. Appert-Collin A, Cotecchia S, Nenniger-Tosato M, Pedrazzini T, Diviani D. The A-kinase anchoring protein (AKAP)-Lbc-signaling complex mediates alphal adrenergic receptor-induced cardiomyocyte hypertrophy. Proc Natl Acad Sci USA 2007, 104, 10140-10145.

30. Diviani D, Lattion AL, Larbi N, Kunapuli P, Pronin A, Benovic JL, Cotecchia S. Effect of different G protein-coupled receptor kinases on phosphorylation and desensitization of the alpha1B-adrenergic receptor. J Biol Chem 1996, 271, 5049-5058.

31. Diviani D, Lattion AL, Cotecchia S. Characterization of the phosphorylation sites involved in $\mathrm{G}$ protein-coupled receptor kinase- and protein kinase C-mediated desensitization of the alphalB-adrenergic receptor. J Biol Chem 1997, 272, 28712-28719.

32. Stanasila L, Abuin L, Dey J, Cotecchia S. Different internalization properties of the alphala- and alphalb-adrenergic receptor subtypes: the potential role of receptor interaction with betaarrestins and AP50. Mol Pharmacol 2008, 74, 562-573.

33. Vázquez-Prado J, Medina LC, Romero-Avila MT, GonzálezEspinosa C, García-Sáinz JA. Norepinephrine- and phorbol ester-induced phosphorylation of alpha(la)-adrenergic receptors. Functional aspects. J Biol Chem 2000, 275, 6553-6559.

34. García-Sáinz JA, Rodríguez-Pérez CE, Romero-Avila MT. Human alpha1D-adrenoceptor phosphorylation and desensitization. Biochem Pharmacol 2004, 67, 1853-1858.

35. De Wire SM, Seungkirl A, Lefkowitz RJ, Shenoy SK. Beta-arrestins and cell signaling. Annu Rev Physiol 2007, 69, 483-510.
36. Pupo AS, Minneman KP. Interaction of neuronal nitric oxide synthase with alpha1-adrenergic receptor subtypes in transfected HEK-293 cells. BMC Pharmacol 2002, 2, 17.

37. Xu Q, Xu N, Zhang T, Zhang H, Li Z, Yin F, Lu Z, Han Q, Zhang Y. Mammalian tolloid alters subcellular localization, internalization, and signaling of alpha(1a)-adrenergic receptors. Mol Pharmacol 2006, 70, 532-541.

38. Hague C, Bernstein LS, Ramineni S, Chen Z, Minneman KP, Hepler JR. Selective inhibition of alpha1A-adrenergic receptor signaling by RGS2 association with the receptor third intracellular loop. J Biol Chem 2005, 280, 27289-27295.

39. Bernstein LS, Ramineni S, Hague C, Cladman W, Chidiac P, Levey AI, Hepler JR. RGS2 binds directly and selectively to the M1 muscarinic acetylcholine receptor third intracellular loop to modulate $\mathrm{Gq} / 11$ alpha signaling. J Biol Chem 2004, 279, 21248-21256.

40. Diviani D, Lattion AL, Abuin L, Staub O, Cotecchia S. The adaptor complex 2 directly interacts with the alpha $1 \mathrm{~b}$-adrenergic receptor and plays a role in receptor endocytosis. J Biol Chem 2003, 278, 19331-19340.

41. Stanasila L, Abuin L, Diviani D, Cotecchia S. Direct interaction of ezrin with the alphalb-adrenergic receptor regulates recycling of the internalized receptors. J Biol Chem 2006, 281, 4354-4363.

42. Pupo AS, Minneman KP. Specific interactions between gC1qR and alphal-adrenoceptor subtypes. J Recept Signal Transduct Res 2003, 23, 185-195.

43. Wang Q, Zhao J, Brady AE, Feng J, Allen PB, Lefkowitz RJ, Greengard P, Limbird LE. Spinophilin blocks arrestin actions in vitro and in vivo at G protein-coupled receptors. Science 2004, 304, 1940-1944.

44. Chen Z, Hague C, Hall RA, Minneman KP. Syntrophins regulate alpha1D-adrenergic receptors through a PDZ domain-mediated interaction. J Biol Chem 2006, 281, 12414-12420.

45. Cavalli A, Lattion AL, Hummler E, Nenniger M, Pedrazzini T, Aubert JF, Michel MC, Yang M, Lembo G, Vecchione C, Mostardini M, Schmidt A, Beermann F, Cotecchia S. Decreased blood pressure response in mice deficient of the alphalb-adrenergic receptor. Proc Natl Acad Sci USA 1997, 94, 11589-11594.

46. Burcelin R, Uldry M, Foretz M, Perrin C, Dacosta A, NennigerTosato M, Seydoux J, Cotecchia S, Thorens B. Impaired glucose homeostasis in mice lacking the alphalb-adrenergic receptor subtype. J Biol Chem 2004, 279, 1108-1115.

47. Auclair A, Drouin C, Cotecchia S, Glowinski J, Tassin JP. 5-HT2A and alphalb-adrenergic receptors entirely mediate dopamine release, locomotor response and behavioural sensitization to opiates and psychostimulants. Eur J Neurosci 2004, 20, 3073-3084.

48. Rokosh DG, Simpson PC. Knockout of the alpha 1A/C-adrenergic receptor subtype: the alpha $1 \mathrm{~A} / \mathrm{C}$ is expressed in resistance arteries and is required to maintain arterial blood pressure. Proc Natl Acad Sci USA 2002, 99, 9474-9479.

49. Tanoue A, Nasa Y, Koshimizu T, Shinoura H, Oshikawa S, Kawai T, Sunada S, Takeo S, Tsujimoto G. The alpha(1D)-adrenergic receptor directly regulates arterial blood pressure via vasoconstriction. J Clin Invest 2002, 109, 765-775.

50. Milano CA, Dolber PC, Rockman HA, Bond RA, Venable ME, Allen LF, Lefkowitz RJ. Myocardial expression of a constitutively active alpha 1B-adrenergic receptor in transgenic mice induces cardiac hypertrophy. Proc Natl Acad Sci USA 1994, 91, 10109-10113.

51. Dorn GW 2nd, Brown JH. Gq signaling in cardiac adaptation and maladaptation. Trends Cardiovasc Med 1999, 9, 26-34.

52. Zuscik MJ, Chalothorn D, Hellard D, Deighan C, McGee A, Daly CJ, Waugh DJ, Ross SA, Gaivin RJ, Morehead AJ, Thomas JD, Plow EF, McGrath JC, Piascik MT, Perez DM. Hypotension, autonomic failure, and cardiac hypertrophy in transgenic mice overexpressing the alpha 1B-adrenergic receptor. J Biol Chem 2001, 276, 13738-13743.

53. O'Connell TD, Ishizaka S, Nakamura A, Swigart PM, Rodrigo MC, Simpson GL, Cotecchia S, Rokosh DG, Grossman W, Foster E, Simpson PC. The alpha(1A/C)- and alpha(1B)adrenergic receptors are required for physiological cardiac hypertrophy in the double-knockout mouse. J Clin Invest 2003, $111,1783-1791$. 
54. Lin F, Owens WA, Chen S, Stevens ME, Kesteven S, Arthur JF, Woodcock EA, Feneley MP, Graham RM. Targeted alpha(1A)adrenergic receptor overexpression induces enhanced cardiac contractility but not hypertrophy. Circ Res 2001, 89, 343-350.

55. Akhter SA, Milano CA, Shotwell KF, Cho MC, Rockman HA, Lefkowitz RJ, Koch WJ. Transgenic mice with cardiac overexpression of alpha1B-adrenergic receptors. In vivo alphal-adrenergic receptor-mediated regulation of beta-adrenergic signaling. J Biol Chem 1997, 272, 21253-21259.
56. Woodcock EA. Roles of $\alpha 1 \mathrm{~A}$ and $\alpha 1 \mathrm{~B}$-adrenoceptors in heart: insights from studies on genetically modified mice. Clin and Exp Pharmacol and Physiol 2007 34, 884-888.

57. Hosoda C, Koshimizu TA, Tanoue A, Nasa Y, Oikawa R, Tomabechi T, Fukuda S, Shinoura H, Oshikawa S, Takeo S, Kitamura T, Cotecchia S, Tsujimoto G. Two alpha1-adrenergic receptor subtypes regulating the vasopressor response have differential roles in blood pressure regulation. Mol Pharmacol 2005, $67,912-922$. 